\title{
Impact of the International Nosocomial Infection Control Consortium (INICC) multidimensional approach on rates of ventilator-associated pneumonia in intensive care units of two hospitals in Kuwait
}

Journal of Infection Prevention 2018, Vol. 19(4) 168-176 (C) The Author(s) 2018 Reprints and permissions: sagepub.co.uk/journalsPermissions.nav DOI: $10.1177 / 17571774 \mid 8759745$ jip.sagepub.com @SAGE

\author{
Haifaa Hassan Al-Mousa', Abeer Aly Omar', Víctor Daniel \\ Rosenthal', Mona Foda Salama ${ }^{3,4}$, Nasser Yehia Aly ${ }^{5,6}$, \\ Mohammad El-Dossoky Noweir ${ }^{5}$, Flavie Maria Rebello ${ }^{3}$, \\ Dennis Malungcot Narciso ${ }^{3}$, Amani Fouad Sayed 5 , \\ Anu Kurian ${ }^{5}$, Sneha Mary George ${ }^{5}$, Amna Mostafa \\ Mohamed $^{5}$, Ruby Jose Ramapurath ${ }^{5}$, Suga Thomas \\ Varghese $^{5}$ and Pablo Wenceslao Orellano ${ }^{2,7}$
}

\section{Abstract}

Objective: To analyse the impact of the International Nosocomial Infection Control Consortium (INICC) multidimensional approach (IMA) on ventilator-associated pneumonia (VAP) rates in three intensive care units (ICUs) from two hospitals in Kuwait City from January 2014 to March 2015.

Design: A prospective, before-after study on 2507 adult ICU patients. During baseline, we performed outcome surveillance of VAP applying CDC/NHSN definitions. During intervention, we implemented the IMA through the INICC Surveillance Online System (ISOS), which included: (1) a bundle of infection prevention interventions; (2) education; (3) outcome surveillance; and (4) feedback on VAP rates and consequences. Logistic regression analysis was performed to estimate the effect of the intervention on VAP, controlling for potential bias.

Results: During baseline, 1990 mechanical ventilator (MV)-days and I4 VAPs were recorded, accounting for 7.0 VAPs per 1000 MV-days. During intervention, $9786 \mathrm{MV}$-days and $35 \mathrm{VAPs}$ were recorded, accounting for 3.0 VAPs per 1000 MV-days. The VAP rate was reduced by $57.1 \%$ (incidence-density ratio $=0.5 \mathrm{I} ; 95 \% \mathrm{Cl}=0.28-0.93 ; \mathrm{p}=0.042$ ). Logistic regression showed a significant reduction in VAP rate during the intervention phase $(O R=0.39,95 \% \mathrm{Cl}=0.18-0.83)$, with $61 \%$ effectiveness.

Conclusions: Implementing IMA through ISOS was associated with a significant reduction in the VAP rate in Kuwait ICUs.

\footnotetext{
'Infection Control Directorate, Ministry of Health, Kuwait City, Kuwait 2International Nosocomial Infection Control Consortium, Buenos Aires, Argentina

3 Mubarak Al Kabir Hospital, Kuwait City, Kuwait

${ }^{4}$ Microbiology and Medical Immunology Department, Mansoura Faculty of Medicine, University of Mansoura, Egypt

${ }^{5}$ Farwaniya Hospital, Kuwait City, Kuwait

${ }^{6}$ Department of Tropical Medicine and Hygiene, Faculty of Medicine,

University of Alexandria, Alexandria, Egypt
}

7Universidad Tecnológica Nacional, Facultad Regional San Nicolás and Consejo Nacional de Investigaciones Científicas y Técnicas, San Nicolás, Argentina

Corresponding author:

Victor Daniel Rosenthal. II de Septiembre 4567, I2th floor, Apt I20I, Buenos Aires, ZIP 1429, Argentina.

Email: victor_rosenthal@inicc.org 


\begin{abstract}
Keywords
Hospital infection, healthcare-acquired infection, device-associated infection, hospital-acquired pneumonia, nosocomial pneumonia, resource-limited countries, critical care, surveillance, incidence density, bundle
\end{abstract}

Date received: 22 November 2016; accepted: 21 January 2018

\section{Background}

Ventilator-associated pneumonias (VAPs) are considered to be among the most serious device-associated infections in the intensive care unit (ICU) setting (Arabi et al., 2008; Rosenthal et al., 2003b). According to studies from developed (Safdar et al., 2005) and limited-resource countries (Arabi et al., 2008; Rosenthal et al., 2005), the most important clinical consequences attributable to VAP are increased mortality rates (Rosenthal et al., 2005), significant morbidity (Bouadma et al., 2012) and increased length of stay (Rosenthal et al., 2005). If economic aspects are considered, VAPs are also responsible for significant increases in healthcare costs, as reported in both developed (Safdar et al., 2005) and limited-resource countries (Rosenthal et al., 2005). Although hospitals in limited-resource countries do implement basic infection control programs, compliance with infection control practices is variable and the burden posed by VAP is not systematically analysed in these settings (Arabi et al., 2008). As reported by the International Nosocomial Infection Control Consortium (INICC) in pooled studies (Rosenthal et al., 2006b, 2008, 2010, 2012b, 2016) and, in particular, studies from Kuwait (Al-Mousa et al., 2016), the rates of VAP have been determined to be 3-5 times higher in resource-limited countries than in more economically developed countries.

It was shown in the scientific literature that the incidence of VAP in developed countries can be substantially prevented and reduced by $>30 \%$ through basic but effective measures, such as those described in the Institute for Healthcare Improvement (IHI) Ventilation Bundle (IHI, 2012): (1) elevation of the head of the bed at $30-45^{\circ}$; (2) daily sedative interruption and daily assessment of readiness to extubate; (3) peptic ulcer disease prophylaxis; (4) deep venous thrombosis prophylaxis; and (5) daily oral care with chlorhexidine (Arabi et al., 2008; Rosenthal, 2011).

Founded in Argentina in 1998, the INICC was the first multinational research network established to control and reduce healthcare-associated infection rates at an international level through the analysis of data collected on a voluntary basis by a pool of hospitals from 66 countries in Latin America, Europe, Eastern Mediterranean, South East Asia, and Western Pacific World Health Organization (WHO) regions (Rosenthal, 2016). The goals of the INICC include the development of a dynamic global hospital network that applies systematic surveillance with standardised definitions and methodologies of CDC/NHSN (CDC/ NHSN, 2013), the promotion of evidence-based infection control practices and the performance of applied infection control research to reduce rates of healthcare-associated infections, associated mortality, excess lengths of stay, costs and bacterial resistance (Rosenthal, 2016).

The present study was aimed to determine the effect of the INICC multidimensional approach (IMA), which included: (1) a bundle of infection prevention practice interventions; (2) education; (3) outcome surveillance; and (4) feedback on VAP rates and consequences, through the use of the INICC Surveillance Online System (ISOS) for the reduction of VAP rates in three adult ICUs of two hospitals in Kuwait City. The main justification for conducting this study was to increase knowledge of the incidence of VAPs in Kuwait and, through its publication, spread awareness on the readily available tools and methods for the reduction of this health burden.

\section{Methods}

\section{Setting and study design}

This prospective, non-controlled before-after study was conducted in three adult ICUs of two INICC member hospitals in Kuwait City. The study period was divided into a three-month 'baseline period' and an 'intervention period' starting from the fourth month of participation. The results obtained from the 'baseline period' were compared to the results obtained during 'intervention period'. Each ICU had an infection control team comprising infection control professionals and medical doctors with formal education and background in internal medicine, critical care, infectious diseases, microbiology and/or hospital epidemiology.

In accordance with the INICC protocol, hospitals' identities were kept confidential and patient personal data were anonymised. Because this was an epidemiological surveillance study which did not include tests of experimental drugs, biomedical devices or products, and patient data were anonymised, informed consent was not necessary according to the ethics committees that evaluated and approved the study.

It is worth clarifying that the methodology of ISOS has been used by INICC members since 2013, although the publication describing it was published in 2016 (Rosenthal, 2016).

\section{Baseline period}

The baseline period was from 1 January 2014 to 31 March 2014. This was a cohort study and each ICU joined the study simultaneously. During the baseline period, only VAP 
Outcome Surveillance was conducted. The length of the baseline period was three months due to the following reasons. (1) The sample size of patients and number of months of data collection during baseline period were sufficient enough to be compared with data from the intervention period. From a statistical perspective, the issue is addressed by considering the changes in rates over time. The relatively short baseline period may impact the standard error of our estimates, but we found that this would not cause a bias in the results, because there would not be systematic differences between the two groups. (2) Our priority was to start intervention as soon as possible and achieve the desired results, such as VAP rate and mortality rate reduction.

\section{Intervention period}

The intervention period started in the fourth month of participation, from 1 April 2014 to March 2015, and included the simultaneous implementation of four components of the IMA, which are described below.

\section{INICC multidimensional approach (IMA)}

In this study, the IMA comprised the simultaneous implementation of the following four components for VAP prevention: (1) a bundle of infection prevention practice interventions; (2) education; (3) outcome surveillance; and (4) feedback on VAP rates and consequences. Although the IMA includes two other components-namely, performance feedback and feedback on VAP rates and consequences (Rosenthal, 2016) - due to budget restrictions in this study, process surveillance was not conducted, and so performance feedback was not provided either.

The contents of the IMA include CDC/NHSN's surveillance methodology, but they also include the collection of other specific patient data essential to increase infection control professionals' sensitivity to check VAP criteria, detect VAPs and avoid underreporting (CDC/NHSN, 2013). According to standard CDC/NHSN methods, numerators are the number of VAPs of each type and denominators are device-days collected from all patients as pooled data, i.e. without determining the number of device-days related to a particular patient and without collecting characteristics per specific patient (CDC/NHSN, 2013). This differs from the IMA in that the design of the cohort study through the INICC methods also includes collecting specific data per patient from all patients, both those with and those without VAP, collecting risk factors of VAPs, such as invasive devices, and surrogates of VAPs, which include, but are not limited to, high temperature, low blood pressure, results of cultures, antibiotic therapy, length of stay and mortality. Moreover, by collecting data on all patients in the ICU, it is possible to match patients with and without VAP by several characteristics to estimate extra length of stay, mortality and cost (Rosenthal, 2016).
The data concerned in the IMA were registered and uploaded to the ISOS. The following modules of the ISOS were used: Cohort VAP surveillance in adult ICU patients and microbiology for adult and paediatric patients (Rosenthal, 2016).

\section{Bundle of infection prevention practice interventions}

The bundles of infection prevention practice interventions were designed following the recommendations and guidelines published by the Society for Health Care Epidemiology of America (SHEA) and the Infectious Diseases Society of America (IDSA) published in 2008 (Marschall et al., 2008) and in 2014 (Yokoe et al., 2014), as well as elements of the IHI Ventilation Bundle (IHI, 2012). These recommendations for VAP prevention are classified into categories regarding the existing scientific evidence, applicability and their prospective economic effects. In total, we implemented 13 infection control measures for VAP prevention.

\section{Components of INICC Infection Control Bundle for VAP prevention}

(1) Adherence to hand-hygiene guidelines; (2) use of noninvasive ventilation whenever possible and minimisation of the duration of ventilation; (3) preferable use of orotracheal instead to nasotracheal intubation; (4) maintenance of an endotracheal cuff pressure of at least $20 \mathrm{~cm} \mathrm{H}_{2} \mathrm{O}$; (5) removal of the condensate from ventilator circuits and keeping the ventilator circuit closed during condensate removal; (6) change of the ventilator circuit only when visibly soiled or malfunctioning; (7) avoidance of gastric overdistention; and (8) use of sterile water to rinse reusable respiratory equipment (Yokoe et al., 2014).

In addition, we also applied the following five elements of the bundle for VAP prevention developed by the IHI (Rosenthal et al., 2003a): (1) elevation of the head of the bed at $30-45^{\circ}$; (2) daily sedative interruption and daily assessment of readiness to extubate; (3) peptic ulcer disease prophylaxis; (4) deep venous thrombosis prophylaxis; and (5) daily oral care with chlorhexidine.

\section{Education}

Education sessions were provided to all healthcare workers (HCWs) in the participating ICUs about the infection control measures contained in the above-described INICC Infection Control Bundle for VAP prevention. During the first phase, at baseline period, the INICC team locally trained the infection control professionals at the hospitals on how to conduct surveillance and upload surveillance data to the ISOS. During intervention, the INICC team locally provided education and training sessions to infection control professionals on the 13 components of the INICC Infection Control Bundle (Rosenthal, 2016) for 
VAP Prevention (training the trainers). In turn, on a monthly basis, infection control professionals at the hospitals trained the ICU teams on how to implement the mentioned bundle components. Education sessions can be measured regarding its efficacy through its impact on rates of compliance with the bundle components. However, as mentioned above, due to budget constraints, we did not conduct process surveillance, which would have evaluated such compliance levels.

\section{Outcome surveillance}

Prospective active outcome surveillance through the ISOS allows the classification of cohort surveillance data into specific module protocols that applied U.S. CDC/NHSN's definitions for VAP published in 2013 (CDC/NHSN, 2013). The site-specific criteria included reporting instructions and provided full explanations integral to their adequate application (Rosenthal, 2016).

Validation of each case was checked and the recorded signs and symptoms of infection and the results of cultures, laboratory and radiographic studies, as well as other tests, were scrutinised to assure that U.S. CDC/NHSN's criteria for VAPs were met (Rosenthal, 2016).

\section{Feedback on VAP rates and consequences}

The infection control professionals generated reports through the ISOS. The ICU HCWs received feedback on VAP rates and their consequences at monthly meetings held by infection control professionals who shared and discussed the results of ISOS. These reports contained several charts and tables that showed a running record of the monthly cohort surveillance data, including patient characteristics, such as age and sex, proportion of VAPs, including pooled means of VAP and of MV device utilisation ratios (DURs), microorganisms profile, bacterial resistance, extra length of stay and extra mortality attributable to VAPs, and benchmark of these rates against standards from the CDC-NHSN report of 2013 (Dudeck et al., 2015), the last INICC Report of 50 countries (Rosenthal et al., 2016), against standards from the Kingdom of Saudi Arabia, and INICC reports from Turkey, India, Colombia and Mexico.

Benchmarking was an important tool to increase the level of awareness of patient outcomes at their ICUs in comparison with other national and international standards, and to enable the infection control professionals and ICU team to focus on the necessary issues and apply specific strategies for the reduction of VAP rates.

\section{Data collection and analysis}

The ISOS meets the criteria set out in the INICC protocol and CDC-NHSN criteria, which were followed by the infection control professionals who collected daily data on
VAPs and denominator data, patient-days and specific device-days in the ICUs.

These data were uploaded to the ISOS, and were used to calculate VAP rates per $1000 \mathrm{MV}$-days, mortality and length of stay, according to the following formulas: (1) MV-days consisted of the total number of days of each patient's exposure to mechanical ventilation; (2) DUR equals the total number of MV-days divided by the total number of beddays; (3) VAP rate per 1000 MV-days was calculated according to CDC/NHSN formula (CDC/NHSN, 2013).

\section{Statistical methods}

INICC Surveillance Online System (ISOS) version 2.0 (Buenos Aires, Argentina) was used to calculate VAP rates and DUR. Patients' characteristics were compared using Fisher's exact test for dichotomous variables and independent Student's t-test for continuous variables; $p$ values $<0.05$ from two-sided tests were considered significant.

We conducted two types of analysis to evaluate the impact of our intervention on VAP rates. First, we performed an analysis to compare the data of the first three months (baseline period) with the remaining pooled months (intervention period), using incidence density ratio (IDR), $95 \%$ confidence interval (CI) and $p$ values. Second, in order to analyse progressive VAP rate reduction, we divided the data into the first three months (baseline period), followed by a follow-up period (intervention period) for the three participating ICUs: a six-month follow-up period for two ICUs and a three-month follow-up period for one ICU. We compared the VAP rates for each follow-up period with the baseline VAP rate. We compared the VAP rates for each follow-up period with the baseline VAP rate.

In order to avoid possible bias related to the observational nature and design of this study, a generalised linear model was employed. Thus, other variables that could influence the results acting as potential confounders or effect modifiers were controlled by analysis. We estimated the effect of the intervention on VAP by means of a logistic regression model. A set of co-variables was included to account for possible interactions and confusion effects. A backward procedure that compares nested models using the Akaike Information Criterion (AIC) was carried out to get the final set of significant co-variables. Collinearity among independent variables was measured using the variance inflation factor (VIF). We calculated the odds ratio (OR) and $95 \% \mathrm{CI}$ for the intervention and MV-days. The effectiveness of the intervention was calculated using the formula: $(1-\mathrm{OR}) \times 100$, where OR is the adjusted OR estimated by the model. All statistical analyses were performed using the $\mathrm{R}$ software version 3.2.2.

\section{Results}

During the study period, we recorded a total of 2507 patients, hospitalised for 14,453 days, with a total of 11,776 
Table I. Patient characteristics, device utilisation and ventilator-associated pneumonia rates during baseline and intervention periods.

\begin{tabular}{|llll|}
\hline Patient characteristics & Baseline period & Intervention period & P value \\
\hline Study period by hospital (months), mean (range) & 3 & $14(13-15)$ & - \\
\hline Patients $(n)$ & 593 & 1914 & - \\
\hline Bed-days $(n)^{*}$ & 3198 & 11,255 & - \\
\hline MV-days $(n)^{\dagger}$ & 1990 & 9786 & - \\
\hline MV duration, mean (SD) & $11.3(12.8)$ & $11.0(14.7)$ & 0.786 \\
\hline DUR ${ }^{\ddagger}$ & 0.68 & 0.78 & 0.000 \\
\hline VAP $(n)$ & 14 & 35 & \\
\hline Incidence rate: VAPs per 1000 MV-days $(95 \%$ Cl) & $7.0(3.8-11.8)$ & $3.6(2.5-5.0)$ & 0.042 \\
\hline
\end{tabular}

*Bed-days are the total number of days that patients are in the ICU during the selected time period.

tMV-days are the total number of days of exposure to mechanical ventilation by all of the patients in the selected population during the selected time period.

tDUR is MV-days divided by the number of bed-days.

$\mathrm{Cl}$, confidence interval; VAP, ventilator-associated pneumonia; MV, mechanical ventilator; SD, standard deviation; DUR, device utilisation ratio.

Table 2. Ventilator-associated pneumonia rates stratified by length of participation of each intensive care unit.

\begin{tabular}{|lllllll}
\hline Months since joining INICC & ICUs $(n)$ & MV-days & VAP & Crude VAP rate/ I000 MV-days (IR) & VAP rate reduction (\%) \\
\hline I-3 months (baseline) & 3 & 1990 & 14 & 7.0 & -- \\
\hline 4-6 months & 3 & 2346 & 10 & 4.3 & 38.6 & 47.1 \\
\hline 7-12 months & 2 & 4081 & 15 & 3.7 & 57.1 & \\
\hline Second year & 2 & 3359 & 10 & 3.0 & .
\end{tabular}

INICC, International Nosocomial Infection Control Consortium; ICUs, intensive care units; VAP, ventilator-associated pneumonia; MV, mechanical ventilator; $\mathbb{I R}$, incidence rate.

MV-days, at two hospitals in Kuwait City, in the following types of adult ICUs: two medical/surgical ICUs (1941 patients) and one coronary ICU (566 patients).

Some patient characteristics, such as age, were similar during both periods (mean age $=51.8$ [18.3] during baseline and 50.1 [19.5] during intervention; $p=0.066$ ). However, sex proportion was significantly different, with more women during the intervention period $(75 \%[n=138]$ male during baseline vs. $65 \%[\mathrm{n}=725]$ male during intervention; $p=0.000$.) Mean MV duration was similar during the baseline and the intervention periods, while MV DUR was significantly higher during the intervention period, which increased the risk of VAP (Table 1).

During the baseline period, we recorded 1990 MV-days, for a mean MV use of 11.3 days and a MV utilisation ratio of 0.68 per bed-day. Merging all data of the intervention period, during the implementation of the INICC multidimensional infection control approach, we recorded 9786 MV-days, for a mean MV use of 11.0 days and an MV utilisation ratio of 0.78 per bed-day. These results show that the difference between the ratio of bed-days and MV-days during intervention was much lower than during baseline
(1.6 vs. 1.15), which would mean that during intervention the patient was much less likely to be mechanically ventilated than during baseline (Table 1).

At baseline, there were 14 VAPs, for an overall rate of 7.0 VAPs per 1000 MV-days. Merging all data of the intervention period, during the implementation of the INICC multidimensional infection control approach, there were 35 VAPs for an incidence rate of 3.6 per $1000 \mathrm{MV}$-days. These results showed an overall VAP rate reduction from baseline by $57.1 \%$, comparing months $1-3$ against all remaining periods $(\mathrm{IDR}=0.51 ; 95 \% \mathrm{CI}=0.28-0.93 ; \mathrm{p}=0.042)($ Table 1$)$.

During the baseline period (1-3 months), the VAP rate was 7 VAPs per 1000 MV-days; during months 4-6, it was 4.3 VAPs per 1000 MV-days; during months 7-12, it was 3.7 VAPs per $1000 \mathrm{MV}$-days; and during months $13-24$, it was 3 VAPs per 1000 MV-days. These results showed a progressive, maintained reduction during all the study period from 7 to 3 VAPs per $1000 \mathrm{MV}$-days (Table 2).

The results of the logistic regression model are presented in Table 3. These results showed a significant reduction in the VAP risk in patients during the intervention period, when controlling for the number of MV-days and the 
Table 3. Results of the logistic regression model showing the effect of the INICC intervention on the ventilator-associated pneumonia rate.

\begin{tabular}{|c|c|c|c|}
\hline Variables & Coeff (SE) & Adjusted OR* (95\% Cl) & $P$ value \\
\hline Period (intervention) & $-0.94 \mid(0.383)$ & $0.39(0.18-0.83)$ & 0.01 \\
\hline MV-days ${ }^{\dagger}$ & $0.067(0.008)$ & $1.07(1.05-1.09)^{\ddagger}$ & $<0.01$ \\
\hline Hospital/ICU & I.627 (0.887) & $2.12(1.01-4.45)$ & 0.04 \\
\hline
\end{tabular}

Table 4. Microorganism related to ventilator-associated pneumonia in adult intensive care units in phase I (baseline period) and phase 2 (intervention period).

\begin{tabular}{|c|c|c|}
\hline Isolated microorganisms (n (\%)) & Baseline & Intervention \\
\hline Acinetobacter baumanii & $7(58.3)$ & $19(59.4)$ \\
\hline Pseudomonas aeruginosa & I (8.3) & $4(12.5)$ \\
\hline Stenotrophomonas spp. & I (8.3) & $2(6.3)$ \\
\hline Klebsiella pneumoniae & I (8.3) & $0(0)$ \\
\hline Serratia marcescens & I (8.3) & $0(0)$ \\
\hline Staphylococcus aureus & I (8.3) & $0(0)$ \\
\hline Candida spp. & $0(0)$ & $3(9.4)$ \\
\hline Enterobacter spp. & $0(0)$ & $2(6.3)$ \\
\hline Escherichia coli & $0(0)$ & I (3.I) \\
\hline Morganella morganii & $0(0)$ & I (3.I) \\
\hline Total & $12(100)$ & $32(100)$ \\
\hline
\end{tabular}

ICU, adult intensive care unit; VAP, ventilator-associated pneumonia.

hospital $/ \mathrm{ICU}(\mathrm{OR}=0.39,95 \% \mathrm{CI}=0.18-0.83)$. The model also detected a significant excess risk for a unit increase in the $\mathrm{MV}(\mathrm{OR}=1.07,95 \% \mathrm{CI}=1.05-1.09)$, and an excess risk associated with one $\mathrm{ICU}(\mathrm{OR}=2.12,95 \% \mathrm{CI}=1.01-$ 4.45). The adjusted effectiveness of the intervention was $61 \%(95 \% \mathrm{CI}=17-82 \%)$. There were no significant interactions detected among predictor variables. Collinearity indices in the final model were low (1.043-1.125), indicating absence of collinearity among the independent variables.

The microorganisms profile is shown in Table 4. The predominant microorganism in both phases was Acinetobacter baumanii.

\section{Discussion}

Within the limited scope of studies addressing the burden of VAPs in Kuwait, the VAP rate found in our study at baseline was similar to the rate of 9 VAPs per $1000 \mathrm{MV}$-days reported by Aly et al. (2008).

In comparison with international VAP rates, the VAP baseline rate found in this study (7.0 per $1000 \mathrm{MV}$-days) was similar to the 6.8 rate determined by the German surveillance system KISS (Geffers and Gastmeier, 2011) and lower than the last international INICC report, data summary of 50 countries for 2010-2015 (13.1 VAPs per 1000 MV-days) (Rosenthal et al., 2016). By contrast, the baseline rate of VAP determined in this study was almost tenfold higher than the U.S. 0.8 VAP rate per 1000 MV-days determined by the CDC/NHSN for 2013 (Dudeck et al., 2015).

During the study period, the high VAP rate at baseline was reduced from 7.0 to 3.0 per $1000 \mathrm{MV}$-days (IDR $=0.51$; $95 \% \mathrm{CI}=0.28-0.93 ; \mathrm{p}=0.042$ ), showing a $57.1 \%$ VAP rate reduction. This reduction was achieved despite the higher patient intrinsic risk during the intervention period shown 
by the statistically significantly higher MV DUR and MV duration means. Additionally, a substantial difference was observed between the ratio of bed-days and MV-days during intervention, which was much lower than during baseline (1.6 vs. 1.15), which would mean that during intervention the patient was much less likely to be mechanically ventilated than during baseline.

References from the literature showing a similar reduction include previous studies performed by INICC in which the implementation of a four- or six-component multidimensional approach for VAP prevention resulted in significant reductions in rates of VAP in Argentina (51.28 vs. 35.50 VAPs per 1000 MV-days) (Rosenthal et al., 2006a), China, amounting to a $79 \%$ cumulative VAP rate reduction during the three-year study period (Tao et al., 2012), Cuba (52.63 vs. 15.32 VAPs per 1000 MV-days ) (Guanche-Garcell et al., 2013), Turkey (31.14 vs. 16.82 VAPs per $1000 \mathrm{MV}$-days) (Leblebicioglu et al., 2013), India (17.43 vs. 10.81 VAPs per 1000 MV-days) (Mehta et al., 2013), Malaysia (27.2 vs. 12.9 VAPs per 1000 MV-days) (Gan et al., 2016) and in the pooled VAP rates of paediatric ICUs (31\% VAP rate reduction) (Rosenthal et al., 2012a), neonatal ICUs (33\% VAP rate reduction) (Rosenthal et al., 2012d) and adult ICUs (55.83\% VAP rate reduction) (Rosenthal et al., 2012c) of limited-resource countries.

The logistic regression analysis showed that the intervention led to a significant reduction in the VAP risk and this relationship was modulated by the number of days spent in MV. Moreover, based on the model's results, the effectiveness of the intervention was $>60 \%$, which means there was an important and statistically significant reduction in the patients' VAP risk associated with the INICC method. The model also showed that one ICU represented an excess risk with respect to the others, a possible indication that the results of the intervention were not uniformly distributed between ICUs.

We consider that through the implementation of the IMA, it was possible to raise HCWs' awareness about the risk of VAP, and hence they were less likely to recommend MV use. This probably led to fewer patients to be mechanically ventilated, which in turn led to the reduction of the likely hood of developing VAP. This increased awareness would also explain the results shown in Table 2 (lower rate of MV in year 2 than in baseline.)

Regarding causative microorganisms we identified a predominance of Acinetobacter baumanii during both periods $(58.3 \%$ and $59.4 \%$ for the baseline and intervention periods, respectively). According to the scientific literature from Kuwait, the predominance of Acinetobacter spp. has been identified among the most opportunistic pathogens that causes serious healthcare-associated complications in ICU patients and multidrug resistance of these pathogens has increased dramatically in hospitalised patients (Vali et al., 2015).

\section{Study limitations}

The main limitation of this study is that our findings cannot be generalised to and are not representative of all ICU patients from Kuwait as they are from three ICUs in two hospitals, and there are over 80 healthcare centres spread over six regions of the country (WHO, 2016). In addition, differences among the ICUs were not examined. However, it was shown that a multidimensional approach is fundamental to fight against the incidence of VAPs in this ICU setting. Second, the setting of a three-month baseline period may be short and might have overestimated the effect of the intervention. Nevertheless, during the baseline period, the sample size was sufficient and the CIs for the baseline rate were narrow. Third, due to budget restrictions, process surveillance, which would have measured the level of performance by HCWs of the bundle of prevention practices, was not recorded, and we were not able to provide performance feedback, nor an analysis to explain the extent to which some interventions were more effective than others in the reduction of VAP rates. Finally, this was not a controlled study and, therefore, it was susceptible to different types of bias. In this regard, the inclusion of the regression analysis helped to control the effect of potential confounders.

\section{Conclusions}

This is the first multicentre study to report a substantial reduction in VAP rates in the ICU setting of Kuwait. The implementation of the IMA resulted in significant reductions in the VAP incidence rate, but this is part of a work in progress, which will continue to show further improvements, because the IMA is now being implemented in an increasing number of hospitals from this country. In addition, these results are significant in at least two major respects: the systematically collected data serve as guidance for strategies to improve patient care practices; and these preventive strategies proven effective in the INICC ICUs of Kuwait can promote a wider acceptance of infection control programmes in hospitals worldwide, leading to significant VAP rate reduction.

\section{Acknowledgements}

The authors thank the many healthcare professionals at each member hospital who assisted with the conduct of surveillance in their hospital; Débora López Burgardt, who works at INICC headquarters in Buenos Aires, and the INICC Advisory Board, Country Directors and Secretaries (Hail M Alabdaley, Yassir Khidir Mohamed, Safaa Abdul Aziz AlKhawaja, Amani Ali El-Kholy, Aamer Ikram, Vineya Rai, María Isabel Villegas Mota, Souha S. Kanj, Hakan Leblebicioglu, Yatin Mehta, Bijie Hu, Lul Raka, Najiba M Abdulrazzaq, Sergio Cimerman, Alfonso J RodríguezMorales, Sofía del Carmen González Collantes, Javier Eduardo Desse, Hernán Diosnel Rodríguez Enciso, Nguyen Viet Hung, Wing Hong Seto, Anucha Apisarnthanarak, Toshihiro Mitsuda, Syed Sattar, William Rutala, William R Jarvis, Russell N Olmsted, 
Carla J Alvarado, Catherine Murphy, Dennis Maki, Nicholas Graves, Patricia Lynch and Didier Pittet), who have so generously supported this unique international infection control network.

\section{Declaration of conflicting interests}

The author(s) declared no potential conflicts of interest with respect to the research, authorship, and/or publication of this article.

\section{Funding}

The author(s) disclosed receipt of the following financial support for the research, authorship, and/or publication of this article: The funding for the activities carried out at INICC headquarters were provided by the corresponding author, Victor D. Rosenthal, and the Foundation to Fight against Nosocomial Infections.

\section{Peer review statement}

Not commissioned; blind peer-reviewed.

\section{References}

Al-Mousa HH, Omar AA, Rosenthal VD, Salama MF, Aly NY, El-Dossoky Noweir M, Rebello FM, Narciso DM, Sayed AF, Kurian A, George SM, Mohamed AM, Ramapurath RJ and Varghese ST. (2016) Device-associated infection rates, bacterial resistance, length of stay, and mortality in Kuwait: International Nosocomial Infection Consortium (INICC) findings. American Journal of Infection Control 44: 444-449.

Aly NY, Al-Mousa HH and Al Asar el SM. (2008) Nosocomial infections in a medical-surgical intensive care unit. Medical Principles and Practice 17: 373-377.

Arabi Y, Al-Shirawi N, Memish Z and Anzueto A. (2008) Ventilatorassociated pneumonia in adults in developing countries: a systematic review. International Journal of Infectious Diseases 12: 505-512.

Bouadma L, Wolff M and Lucet JC. (2012) Ventilator-associated pneumonia and its prevention. Current Opinion in Infectious Diseases 25: 395-404.

CDC/NHSN. (2013) CDC/NHSN surveillance definition of health careassociated infection and criteria for specific types of infections in the acute care setting. Available at: http://www.cdc.gov/nhsn/.

Dudeck MA, Edwards JR, Allen-Bridson K, Gross C, Malpiedi PJ, Peterson KD, Pollock DA, Weiner LM and Sievert DM. (2015) National Healthcare Safety Network report, data summary for 2013, Device-associated Module. American Journal of Infection Control 43: 206-221

Gan CS, Rai V, Rosenthal VD, et al. (2016) Multicenter study in Malaysia: Impact of a Multidimensional International Nosocomial Infection Control Consortium (INICC) approach on ventilator-associated pneumonia rates and mortality in intensive care units. Canadian Journal of Infection Control 31: 107-112.

Geffers C and Gastmeier P. (2011) Nosocomial infections and multidrugresistant organisms in Germany: epidemiological data from KISS (the Hospital Infection Surveillance System). Deutsches Arzteblatt International 108: 87-93.

Guanche-Garcell H, Morales-Perez C and Rosenthal VD. (2013) Effectiveness of a multidimensional approach for the prevention of ventilator-associated pneumonia in an adult intensive care unit in Cuba: findings of the International Nosocomial Infection Control Consortium (INICC). Journal of Infection and Public Health 6: 98-107.

IHI. (2012) How-to Guide: Prevent Ventilator-Associated Pneumonia. Cambridge, MA: Institute for Healthcare Improvement. Available at www.ihi.org.
Leblebicioglu H, Yalcin AN, Rosenthal VD, Koksal I, Sirmatel F, Unal S, Turgut H, Ozdemir D, Ersoz G, Uzun C, Ulusoy S, Esen S, Ulger F, Dilek A, Yilmaz H, Turhan O, Gunay N, Gumus E, Dursun O, Yylmaz G, Kaya S, Ulusoy H, Cengiz M, Yilmaz L, Yildirim G, Topeli A, Sacar S, Sungurtekin H, Ugurcan D, Geyik MF, Sahin A, Erdogan S, Kaya A, Kuyucu N, Arda B and Bacakoglu F. (2013) Effectiveness of a multidimensional approach for prevention of ventilator-associated pneumonia in 11 adult intensive care units from 10 cities of Turkey: findings of the International Nosocomial Infection Control Consortium (INICC). Infection 41: 447-456.

Marschall J, Mermel LA, Classen D, Arias KM, Podgorny K, Anderson DJ, Burstin H, Calfee DP, Coffin SE, Dubberke ER, Fraser V, Gerding DN, Griffin FA, Gross P, Kaye KS, Klompas M, Lo E, Nicolle L, Pegues DA, Perl TM, Saint S, Salgado CD, Weinstein RA, Wise R and Yokoe DS. (2008) Strategies to prevent central line-associated bloodstream infections in acute care hospitals. Infection Control and Hospital Epidemiology 29 Suppl 1: S22-30.

Mehta Y, Jaggi N, Rosenthal VD, Rodrigues C, Todi SK, Saini N, Udwadia FE, Karlekar A, Kothari V, Myatra SN, Chakravarthy M, Singh S, Dwivedy A, Sen N and Sahu S. (2013) Effectiveness of a multidimensional approach for prevention of ventilator-associated pneumonia in 21 adult intensive-care units from 10 cities in India: findings of the International Nosocomial Infection Control Consortium (INICC). Epidemiology and Infection 141: 2483-2491.

Rosenthal VD. (2011) Health-care-associated infections in developing countries. Lancet 377: 186-188.

Rosenthal VD. (2016) International Nosocomial Infection Control Consortium (INICC) resources: INICC multidimensional approach and INICC surveillance online system. American Journal of Infection Control 44: e81-90.

Rosenthal VD, Al-Abdely HM, El-Kholy AA, AlKhawaja SAA, Leblebicioglu H, Mehta Y, Rai V, Hung NV, Kanj SS, Salama MF, Salgado-Yepez E, Elahi N, Morfin Otero R, Apisarnthanarak A, De Carvalho BM, Ider BE, Fisher D, Buenaflor MCSG, Petrov MM, Quesada-Mora AM, Zand F, Gurskis V, Anguseva T, Ikram A, Aguilar de, Moros D, Duszynska W, Mejia N, Horhat FG, Belskiy V, Mioljevic V, Di Silvestre G, Furova K, Ramos-Ortiz GY, Gamar Elanbya MO, Satari HI, Gupta U, Dendane T, Raka L, Guanche-Garcell H, Hu B, Padgett D, Jayatilleke K, Ben Jaballah N, Apostolopoulou E, Prudencio Leon WE, Sepulveda-Chavez A, Telechea HM, Trotter A, Alvarez-Moreno C and Kushner-Davalos L. (2016) International Nosocomial Infection Control Consortium report, data summary of 50 countries for 2010-2015: Device-associated module. American Journal of Infection Control 44: 1495-1504.

Rosenthal VD, Alvarez-Moreno C, Villamil-Gomez W, Singh S, Ramachandran B, Navoa-Ng JA, Duenas L, Yalcin AN, Ersoz G, Menco A, Arrieta P, Bran-de Casares AC, de Jesus Machuca L, Radhakrishnan K, Villanueva VD, Tolentino MC, Turhan O, Keskin S, Gumus E, Dursun O, Kaya A and Kuyucu N. (2012a) Effectiveness of a multidimensional approach to reduce ventilator-associated pneumonia in pediatric intensive care units of 5 developing countries: International Nosocomial Infection Control Consortium findings. American Journal of Infection Control 40: 497-501.

Rosenthal VD, Bijie H, Maki DG, Mehta Y, Apisarnthanarak A, Medeiros EA, Leblebicioglu H, Fisher D, Alvarez-Moreno C, Khader IA, Del Rocio Gonzalez Martinez M, Cuellar LE, Navoa-Ng JA, Abougal R, Guanche Garcell H, Mitrev Z, Pirez Garcia MC, Hamdi A, Duenas L, Cancel E, Gurskis V, Rasslan O, Ahmed A, Kanj SS, Ugalde OC, Mapp T, Raka L, Yuet Meng C, Thu Ie TA, Ghazal S, Gikas A, Narvaez LP, Mejia N, Hadjieva N, Gamar Elanbya MO, Guzman Siritt ME, Jayatilleke K and INICC members. (2012b) International Nosocomial Infection Control Consortium (INICC) report, data summary of 36 countries, for 2004-2009. American Journal of Infection Control 40: 396-407.

Rosenthal VD, Guzman S and Crnich C. (2006a) Impact of an infection control program on rates of ventilator-associated pneumonia in 
intensive care units in 2 Argentinean hospitals. American Journal of Infection Control 34: 58-63.

Rosenthal VD, Guzman S, Migone O and Crnich CJ. (2003a) The attributable cost, length of hospital stay, and mortality of central line-associated bloodstream infection in intensive care departments in Argentina: A prospective, matched analysis. American Journal of Infection Control 31: 475-480.

Rosenthal VD, Guzman S, Migone O and Safdar N. (2005) The attributable cost and length of hospital stay because of nosocomial pneumonia in intensive care units in 3 hospitals in Argentina: a prospective, matched analysis. American Journal of Infection Control 33: 157-161.

Rosenthal VD, Guzman S and Orellano PW. (2003b) Nosocomial infections in medical-surgical intensive care units in Argentina: attributable mortality and length of stay. American Journal of Infection Control 31: 291-295.

Rosenthal VD, Maki DG, Jamulitrat S, Medeiros EA, Todi SK, Gomez DY, Leblebicioglu H, Abu Khader I, Miranda Novales MG, Berba R, Ramirez Wong FM, Barkat A, Pino OR, Duenas L, Mitrev Z, Bijie H, Gurskis V, Kanj SS, Mapp T, Hidalgo RF, Ben Jaballah N, Raka L, Gikas A, Ahmed A, Thu Ie TA, Guzman Siritt ME and INICC members. (2010) International Nosocomial Infection Control Consortium (INICC) report, data summary for 2003-2008, issued June 2009. American Journal of Infection Control 38: 95-104.

Rosenthal VD, Maki DG, Mehta A, Alvarez-Moreno C, Leblebicioglu H, Higuera F, Cuellar LE, Madani N, Mitrev Z, Duenas L, Navoa-Ng JA, Garcell HG, Raka L, Hidalgo RF, Medeiros EA, Kanj SS, Abubakar S, Nercelles P, Pratesi RD and International Nosocomial Infection Control Consortium Members. (2008) International Nosocomial Infection Control Consortium report, data summary for 2002-2007, issued January 2008. American Journal of Infection Control 36: 627-637.

Rosenthal VD, Maki DG, Salomao R, Moreno CA, Mehta Y, Higuera F, Cuellar LE, Arikan OA, Abougal R, Leblebicioglu $\mathrm{H}$ and International Nosocomial Infection Control Consortium. (2006b) Device-associated nosocomial infections in 55 intensive care units of 8 developing countries. Annals of Internal Medicine 145: 582-591.

Rosenthal VD, Rodrigues C, Alvarez-Moreno C, Madani N, Mitrev Z, Ye G, Salomao R, Ulger F, Guanche-Garcell H, Kanj SS, Cuellar
LE, Higuera F, Mapp T, Fernandez-Hidalgo R and INICC members. (2012c) Effectiveness of a multidimensional approach for prevention of ventilator-associated pneumonia in adult intensive care units from 14 developing countries of four continents: findings of the International Nosocomial Infection Control Consortium. Critical Care Medicine 40: 3121-3128.

Rosenthal VD, Rodriguez-Calderon ME, Rodriguez-Ferrer M, Singhal T, Pawar M, Sobreyra-Oropeza M, Barkat A, Atencio-Espinoza T, Berba R, Navoa-Ng JA, Duenas L, Ben Jaballah N, Ozdemir D, Ersoz G and Aygun C. (2012d) Findings of the International Nosocomial Infection Control Consortium (INICC), Part II: Impact of a multidimensional strategy to reduce ventilator-associated pneumonia in neonatal intensive care units in 10 developing countries. Infection Control and Hospital Epidemiology 33: 704-710.

Safdar N, Dezfulian C, Collard HR and Saint S. (2005) Clinical and economic consequences of ventilator-associated pneumonia: a systematic review. Critical Care Medicine 33: 2184-2193.

Tao L, Hu B, Rosenthal VD, Zhang Y, Gao X and He L. (2012 Impact of a multidimensional approach on ventilator-associated pneumonia rates in a hospital of Shanghai: findings of the International Nosocomial Infection Control Consortium. Journal of Critical Care 27: 440-446.

Vali L, Dashti K, Opazo-Capurro AF, Dashti AA, Al Obaid K and Evans BA. (2015) Diversity of multi-drug resistant Acinetobacter baumannii population in a major hospital in Kuwait. Front Microbiol 6: 743 .

WHO. (2016) Health System Profile Kuwait. Geneva: WHO. Available at: http://www.emro.who.int/human-resources-observatory/countries/ country-profile.html.

Yokoe DS, Anderson DJ, Berenholtz SM, Calfee DP, Dubberke ER, Ellingson KD, Gerding DN, Haas JP, Kaye KS, Klompas M, Lo E, Marschall J, Mermel LA, Nicolle LE, Salgado CD, Bryant K, Classen D, Crist K, Deloney VM, Fishman NO, Foster N, Goldmann DA, Humphreys E, Jernigan JA, Padberg J, Perl TM, Podgorny K, Septimus EJ, VanAmringe M, Weaver T, Weinstein RA, Wise R and Maragakis LL. (2014) A compendium of strategies to prevent healthcare-associated infections in acute care hospitals: 2014 updates. American Journal of Infection Control 42: 820-828. 